\title{
Pre-operative pyuria predicts tumor recurrence in patients undergoing transurethral resection of bladder tumor with post-operative instillation of BCG
}

\author{
Khizar Hayat Gondala, Majed Saeed ${ }^{\text {, }}$,Syed Atif Hussainc, Rana Ata ur Rehman ${ }^{\text {, }}$, Ali Shandar Durrani ${ }^{e}$, \\ Muhammad Raheem Sajjad \\ aProfessor, Department of Urology, Sir Ganga Ram Hospital Lahore. \\ ${ }^{\mathrm{b}}$ Registrar, Department of Urology, Sir Ganga Ram Hospital Lahore. \\ 'Assistant Professor, Department of Urology, Shaikh Zayed Hospital Rahim Yar Khan. \\ ${ }^{\mathrm{d}}$ Assistant Professor, Department of Urology, Nishtar Hospital Multan. \\ eSenior Registrar, Department of Urology, Shaikh Zayed Hospital Lahore. \\ fSenior Registrar, Department of Urology, Sir Ganga Ram Hospital Lahore. \\ *Corresponding Author's e-mail: dratifqme@gmail.com
}

\begin{abstract}
BACKGROUND \& OBJECTIVE: In Pakistan, urinary bladder cancer is one of the top ten malignancies. The most important concern after its treatment is tumor recurrence. Recent literature claimed that pre-operative pyuria in patients undergoing transurethral resection of bladder tumor was associated with significantly higher frequency of recurrence. However, there was controversy in existing literature and no such local published material was available which necessitated the present study. To determine the frequency of pre-operative pyuria in patients undergoing transurethral resection of bladder tumor for non-muscle invasive bladder cancer (NMIBC) with post-operative instillation of Bacillus Calmette Guerin (BCG) and to compare the frequency of tumor recurrence in patients with and without pre-operative pyuria.

METHODOLOGY: It was a comparative study. This study involved 280 patients of both genders aged between $20-80$ years. Pre-operative pyuria was diagnosed if early morning midstream urine specimen showed $\geq 10$ white blood cells/HPF. Outcome variable was frequency of recurrence after 12 weeks of treatment on check cystoscopy.

RESULTS: The mean age of the patients was $57.1 \pm 8.5$ years. There were $236(84.3 \%)$ male and $44(15.7 \%)$ female patients in the study. 155 (55.4\%) patients were tobacco smoker. Pre-operative pyuria was diagnosed in 127 (45.4\%) patients while tumor recurrence was observed in $183(65.4 \%)$ patients. The frequency of tumor recurrence was significantly higher in patients with pre-operative pyuria $(85.8 \%$ vs. $48.4 \%$; $<<0.001)$.

CONCLUSION: Pre-operative pyuria was a frequent finding in patients with non-muscle invasive bladder tumor and was associated with higher frequency of tumor recurrence which warrants routine screening of such patients for pyuria and increased frequency of tumor recurrence.

KEY WORDS: Transurethral Resection of Bladder Tumor, Pyuria, Tumor Recurrence.

\section{INTRODUCTION}

In Pakistan, urinary bladder cancer is one of the top ten malignancies in men and most common malignancy in both men and women ${ }^{[1]}$. Many risk factors have been identified and the most frequent risk factor in Pakistan is cigarette smoking which accounts for $50 \%$ and $31 \%$ of bladder cancers in men and women respectively ${ }^{[1,2]}$. Individuals at additional risk include those who work in the dye, rubber, leather and aluminum industries ${ }^{[2]}$. Bladder cancer is classified as non-muscle invasive bladder cancer (NMIBC), pTa and pT1 and muscle invasive bladder cancer (MIBC) pT2 to pT4.

Since its introduction, BCG has become one of the most successful immunotherapy for non-muscle invasive bladder cancer (NMIBC) $)^{[3-5]}$.

As far any other cancer, after treatment tumor recurrence is the most important concern; frequency of which has been reported as high as $40.0 \%{ }^{[3]}$. Recurrence of tumor warrants a change in treatment plan and is associated with poor prognosis of patient. Currently, cystectomy is recommended as the standard of care after BCG failure in patients with NMIBC and cancer-specific survival has been reported to be over $90 \%{ }^{[4,5]}$. Identification of patients at higher risk of tumor recurrence is therefore utmost important while treating NMIBC and is an area of hot scientific research. Reports showed that $49.0 \%$ patients receiving BCG post TURBT had pre-operative pyuria and that tumor recurrence was significantly higher in patients with pre-operative pyuria $(87.9 \%$ vs. $59.0 \%$; $<0.001)$ as compared to those without pre-operative pyuria ${ }^{[6]}$.
\end{abstract}

Gondal KH, Saeed M, Hussain SA, Rehman AR, Durrani AS, Sajjad MR. Pre-operative pyuria predicts tumor recurrence in patients undergoing transurethral resection of bladder tumor with post-operative instillation of BCG. Journal of University Medical \& Dental College. 2021;12(4):257-261 
In a similar study, Azuma et al., ${ }^{[7]}$ reported the frequency of pre-operative pyuria to be $24.0 \%$ in patients receiving BCG post TURBT and reported the frequency of tumor recurrence to be significantly higher among such patients ( $81.0 \%$ vs. $42.0 \% ; \mathrm{p}<0.0001)$ as compared to those without pre-operative pyuria.

In the light of this evidence, pre-operative pyuria appears to be associated with tumor recurrence and therefore poor prognosis of patients receiving BCG post TURBT for NMIBC. However, the evidence is currently limited to only 2 studies conducted in Japanese population only while there is no other international or local published material. Furthermore, another study in Japanese patients again by Fukushima et al., ${ }^{[8]}$ reported that pre-operative pyuria may have protective effect against intravesical recurrence as they observed significantly lower frequency of recurrence in patients with pre-operative pyuria (31.0\% vs. $50.0 \%$; $\mathrm{p}=0.024$ ) as compared to those without pyuria.

Due to this conflict in existing research evidence and lack of local published material, the purpose of the current study is to determine the frequency of pre-operative pyuria and its relationship with tumor recurrence. The results of the present study may help in the pre-operative identification of high-risk patients for recurrence so that optimal measures can be taken to timely identify and intervene in such cases to improve the patient outcome.

\section{METHODOLOGY}

It was a comparative study. Sample size of 280 patients was calculated with $95 \%$ confidence level and $6 \%$ margin of error while taking expected frequency of pre-operative pyuria to be $49.0 \%$ in patients undergoing TURBT with instillation of BCG ${ }^{[6]}$. Patients were selected by nonprobability, consecutive sampling.

Inclusion Criteria was patients of both sex groups with ages in the range of 20-80 years who were diagnosed with non-muscle invasive bladder tumour (as per operational definition) and underwent transurethral resection of bladder tumour with instillation of BCG.

Exclusion criteria was patients with incomplete excision of primary tumor on histopathological examination of resected specimen (no tumor free margins), History of previous TURBT, pTa low grade, BCG or Mitomycin-C therapy (as per history and clinical record), patients currently on immunosuppressive drugs like steroids and chemotherapy for some other cancer (as per history and clinical record) or HIV positive patients (on routine pre-operative screening from blood bank) and patients having history of trauma, or surgical procedure of genitourinary track in past 2 years (as per history and clinical record).

Two eighty patients admitted with NMIBC and planned for intravesical instillation of BCG post TURBT who fulfilled the above criteria were counseled and explained the details of the study. Indications of BCG instillation is NIMBC, pTa high grade and pT1.Written informed consent and detailed history was taken from each patient. Routine pre-operative workup was done and the presence or absence of pyuria waa noted as per operational definition.

Patients underwent transurethral resection of bladder tumor performed using resectoscope and $80 \mathrm{mg}$ of Bacillus Calmette-Guérin (BCG) diluted in $40 \mathrm{ml}$ normal saline was instilled in the urinary bladder via Foley catheter starting two weeks postoperatively once a week for six weeks and was left inside for two hours. Patients were evaluated after 12 weeks of treatment using cystoscope and recurrence was labeled as per operational definition.

Patient's demographic details along with study variables were noted in a predesigned proforma (attached) by the candidate himself. All the surgeries and post-operative cystoscopic evaluations were performed by a single cystoscopic surgeon ( $\geq 10$ years' experience), all the labs were acquired from the same lab (hospital lab free for patients) and all the pre- and post-operative care was done by a single resident to eliminate bias. Confounding variables were controlled by exclusion. Chi-square test was used to analyze the cross tabulation among the Tumor Recurrence and Pre-Operative Pyuria in table V. Also applied among the Age Groups and Pyuria in table-VI.

\section{RESULTS}

The age of the patients ranged from 35 years to 80 years with a mean of $57.1 \pm 8.5$ years. Most of the patients were aged between $50-59$ years $(56.0 \%)$ followed by $\geq 60$ years $(30.4 \%)$ and $\leq 49$ years $(13.6 \%)$. There were $236(84.3 \%)$ male and $44(15.7 \%)$ female patients in the study group with a male to female ratio of 5.4:1. $155(55.4 \%)$ patients were tobacco smoker. Tumor size ranged from $1 \mathrm{~cm}$ to $4 \mathrm{~cm}$ with a mean of $2.4 \pm 1.1 \mathrm{~cm} .74 .3 \%$ patients had tumor size $\leq 3 \mathrm{~cm}$ followed by $25.7 \%$ patients with tumor size $>3 \mathrm{~cm}$. Duration of disease ranged from 1 to 6 months with a mean of $3.5 \pm 1.6$ months.

Tumor recurrence was observed in $183(65.4 \%)$ patients as shown in Table-III. The frequency of tumor recurrence was significantly higher in patients with pre-operative pyuria $(85.8 \%$ vs. $48.4 \% ; p<0.001)$ as compared to those without pre-operative pyuria as shown in Table-V. Similar significant difference was observed across various subgroups based on patient's age, gender, smoking status and tumor size and duration as shown in Tables-VI.

W

Table-I: Frequency of Pre-operative Pyuria in Patients with NMIBC undergoing TURBT with Post-operative Instillation of $\mathrm{BCG} \mathbf{n}=\mathbf{2 8 0}$.

\begin{tabular}{ccc}
\hline $\begin{array}{c}\text { Pre-Operative } \\
\text { Pyuria }\end{array}$ & Frequency (n) & Percent (\%) \\
\hline Yes & 127 & 45.4 \\
No & 153 & 54.6 \\
Total & 280 & 100 \\
\hline
\end{tabular}


Table-II: Frequency of Pre-operative Pyuria across various Subgroups $\mathbf{n}=\mathbf{2 8 0}$.

\begin{tabular}{|ccc}
\hline Characteristics & n & Pyuria n(\%) \\
\hline Age & & \\
$\leq 49$ years & 38 & $17(44.7 \%)$ \\
$50-59$ years & 157 & $71(45.2 \%)$ \\
$\geq 60$ years & 85 & $39(45.9 \%)$ \\
\hline Gender & & \\
Male & 236 & $107(45.3 \%)$ \\
Female & 44 & $20(45.5 \%)$ \\
\hline Tobacco Smoker & & \\
Yes & 155 & $71(45.8 \%)$ \\
No & 125 & $56(44.8 \%)$ \\
\hline Tumor Size & & \\
$\leq 3$ cm & 208 & $93(44.7 \%)$ \\
$>3$ cm & 72 & $34(47.2 \%)$ \\
\hline Duration of Disease & & \\
\hline $1-3$ months & 133 & $59(44.4 \%)$ \\
$4-6$ months & 147 & $68(46.3 \%)$ \\
\hline
\end{tabular}

Table-III: Frequency of Recurrence in Patients with NMIBC undergoing TURBT with Post-operative Instillation of BCG $\mathrm{n}=\mathbf{2 8 0}$. W

\begin{tabular}{ccc}
\hline Tumor Recurrence & Frequency (n) & Percent (\%) \\
\hline Yes & 183 & 65.4 \\
No & 97 & 34.6 \\
Total & 280 & 100 \\
\hline
\end{tabular}

Table-IV: Frequency of Tumor Recurrence across various Subgroups $\mathbf{n}=\mathbf{2 8 0}$.

\begin{tabular}{|c|c|c|}
\hline Characteristics & n & Recurrence n(\%) \\
\hline \multicolumn{3}{|l|}{ Age } \\
\hline$\leq 49$ years & 38 & $24(63.2 \%)$ \\
\hline $50-59$ years & 157 & $102(65.0 \%)$ \\
\hline$\geq 60$ years & 85 & $57(67.1 \%)$ \\
\hline \multicolumn{3}{|l|}{ Gender } \\
\hline Male & 236 & $154(65.3 \%)$ \\
\hline Female & 44 & $29(65.9 \%)$ \\
\hline \multicolumn{3}{|l|}{$\begin{array}{l}\text { Tobacco } \\
\text { Smoker }\end{array}$} \\
\hline Yes & 155 & $104(67.1 \%)$ \\
\hline No & 125 & $79(63.2 \%)$ \\
\hline \multicolumn{3}{|l|}{ Tumor Size } \\
\hline$\leq 3 \mathrm{~cm}$ & 208 & $136(65.4 \%)$ \\
\hline$>3 \mathrm{~cm}$ & 72 & $47(65.3 \%)$ \\
\hline \multicolumn{3}{|l|}{$\begin{array}{c}\text { Duration of } \\
\text { Disease }\end{array}$} \\
\hline 1-3 months & 133 & $83(62.4 \%)$ \\
\hline 4-6 months & 147 & $100(68.0 \%)$ \\
\hline
\end{tabular}

Table-V: Comparison of Tumor Recurrence between Patients with and without Pre-operative Pyuria $\mathbf{n}=\mathbf{2 8 0}$.

\begin{tabular}{cccc}
\hline Tumor Recurrence & \multicolumn{2}{c}{ Pre-Operative Pyuria } & p-value \\
\hline & $\begin{array}{c}\text { Yes } \\
(\mathbf{n}=\mathbf{1 2 7})\end{array}$ & $\begin{array}{c}\text { No } \\
(\mathbf{n}=\mathbf{1 5 3})\end{array}$ & \\
Yes $(\mathbf{n = 1 8 3})$ & Male & Female & $<0.001^{*}$ \\
No (n=97) & $24(49.0 \%)$ & $47(58.0 \%)$ & \\
Total & $25(51.0 \%)$ & $34(42.0 \%)$ &
\end{tabular}

Chi-square test, * observed difference was statistically significant

Table-VI: Comparison of Tumor Recurrence between Patients with and without Pre-operative Pyuria across Age Groups n=280.

\begin{tabular}{|c|c|c|c|c|c|}
\hline \multirow{2}{*}{$\begin{array}{l}\text { Age } \\
\text { Groups }\end{array}$} & \multicolumn{2}{|c|}{ Recurrence } & \multirow{2}{*}{$\begin{array}{c}\text { Pyuria } \\
\text { No } \\
(\mathbf{1 5 3})\end{array}$} & \multirow[t]{2}{*}{ Total } & \multirow[t]{2}{*}{ p-value } \\
\hline & & $\begin{array}{c}\text { Yes } \\
(n=127)\end{array}$ & & & \\
\hline \multirow{3}{*}{$\begin{array}{c}\leq 49 \text { years } \\
(\mathrm{n}=38)\end{array}$} & Yes & $14(82.4)$ & $10(47.6)$ & $24(63.2)$ & \multirow{3}{*}{$0.027 *$} \\
\hline & No & $3(17.6)$ & $11(52.4)$ & $14(36.8)$ & \\
\hline & Total & $\begin{array}{c}57 \\
(67.1 \%)\end{array}$ & $21(100)$ & $38(100)$ & \\
\hline \multirow{3}{*}{$\begin{array}{c}50-59 \text { years } \\
(\mathrm{n}=157)\end{array}$} & Yes & $61(85.9)$ & $41(47.7)$ & $102(65)$ & \multirow{3}{*}{$<0.001 *$} \\
\hline & No & $10(14.1)$ & $45(52.3)$ & $55(35)$ & \\
\hline & Total & $71(100)$ & $86(100)$ & $157(100)$ & \\
\hline \multirow{3}{*}{$\begin{array}{l}\geq 60 \text { years } \\
(\mathrm{n}=85)\end{array}$} & Yes & $34(87.2)$ & $23(50)$ & $57(67.1)$ & \multirow{3}{*}{$<0.001^{*}$} \\
\hline & No & $5(12.8)$ & $23(50)$ & $28(32.9)$ & \\
\hline & Total & $39(100)$ & $46(100)$ & $85(100)$ & \\
\hline
\end{tabular}

Chi-square test, *observed difference was statistically significant.

\section{DISCUSSION}

In Pakistan, urinary bladder cancer is one of the top ten malignancies in men and most common malignancy in both men and women ${ }^{[1]}$. As with any other cancer, the most important concern after treatment is tumor recurrence which is associated with poor prognosis of patient ${ }^{[3]}$. Identification of patients at higher risk of tumor recurrence is therefore utmost important while treating non-muscle invasive bladder cancer (NMIBC) and is an area of hot scientific research ${ }^{[4,5]}$. Recent literature claimed that pre-operative pyuria among patients undergoing transurethral resection of bladder tumor (TURBT) was associated with significantly higher frequency of recurrence ${ }^{[6,7]}$. However, there was controversy in the existing literature ${ }^{[6-8]}$ while no such local published material was available which necessitated the present study.

In the present study, the mean age of the patients was $57.1 \pm 8.5$ years. Another study reported comparable mean age of $57.5 \pm 12.91$ years in patients presenting with bladder tumor at Social Security Hospital (PESSI) Lahore ${ }^{[9]}$. A similar mean age of $56.65 \pm 13.38$ years has also been reported ${ }^{[10]}$ among such patients presenting at multiple oncology centers 
of Pakistan. A comparable mean age of $57.5 \pm 8.6$ years has been reported ${ }^{[11]}$ among such patients undergoing TURBT at Sindh Institute of Urology and Transplantation, Karachi. Singh et al reported comparable mean age of $59.88 \pm .7$ years among Indian patients ${ }^{[12]}$.

We observed that most of the patients were aged between 50 -59 years $(56.0 \%)$ followed by $\geq 60$ years $(30.4 \%)$ and $\leq 49$ years $(13.6 \%)$. Our observation is in line with that Altaf $\mathrm{J}^{[13]}$ who reported that $60 \%$ of such patients were aged between $50-59$ years followed by $26.3 \%$ patients aged 60 years and above while only $13.7 \%$ patients were aged under 49 years at Liaquat University of Medical and Health Sciences, Jamshoro. Similar frequency of these age groups; $50-59$ years $(56.0 \%), \geq 60$ years $(30.6 \%)$ and $\leq 49$ years $(13.4 \%)$ has also been reported by ${ }^{[14]}$ among Iraqi patients with bladder tumor.

In the present study, there were $236(84.3 \%)$ male and 44 (15.7\%) female patients in the study group with a male to female ratio of 5.4:1. A number of other local studies; Naeem et al. ${ }^{[9]}$ (5.3:1), Mubarak et al. ${ }^{[1]}$ (5.3:1) and Altaf et al. ${ }^{[13]}(5.7: 1)$ have also reported similar male predominance in Pakistani patients with bladder tumor. A relatively higher male predominance with a male to female ratio of $6.4: 1$ has been reported by Biswas et al., ${ }^{[15]}$ among Indian patients. We observed that $55.4 \%$ of such patients were tobacco smokers. Chughtai et al., ${ }^{[10]}$ observed similar frequency of tobacco smoking among bladder tumor patients and reported it to be $54.7 \%$. Similar results have also been published by Naeem et al., ${ }^{[9]}$ and Singh et al., ${ }^{[12]}$ who reported that $57.4 \%$ and $50.0 \%$ of bladder tumor patients respectively were tobacco smokers. In the present study, $74.3 \%$ patients had tumor size $\leq 3 \mathrm{~cm}$ followed by $25.7 \%$ patients with tumor size $>3 \mathrm{~cm}$. A similar frequency of tumor size $\leq 3 \mathrm{~cm}(73.7 \%)$ and $>3$ $\mathrm{cm}(26.3 \%)$ has been reported previously ${ }^{[16]}$ in line with the present study.

In the present study, pre-operative pyuria was diagnosed in $45.4 \%$ patients. A similar frequency of pre-operative pyuria has been observed ${ }^{[8]}$ who reported it to be $43.0 \%$ in Japanese patients with bladder tumor. In two other Japanese studies, Mugiya et al ${ }^{[17]}$ and Satakeet al. ${ }^{[6]}$ reported the frequency of pre-operative pyuria to be $46.5 \%$ and $49.0 \%$ respectively.

We observed tumor recurrence in $65.4 \%$ patients following TURBT and installation of BCG. The frequency of tumor recurrence was significantly higher in patients with preoperative pyuria $(85.8 \%$ vs. $48.4 \%$; p-value $<0.001)$ as compared to those without pre-operative pyuria. Our observation is in line with that of ${ }^{[7]}$ who also reported that the frequency of tumor recurrence was significantly higher among patients with pre-operative pyuria ( $81.0 \%$ vs. $42.0 \%$; $\mathrm{p}<0.001)$ as compared to those without pre-operative pyuria. Similar results have also been reported ${ }^{[6]}(87.9 \%$ vs. $59.0 \%$; $\mathrm{p}<0.001)$.

A lower incidence in bladder cancer has been reported in Korea as compared to western countries, being the second most common urological cancer in Koreans ${ }^{[18]}$. Some clinicians used prophylactic antibiotics as cystoscopy can cause mucosal injury and lower UTI. However, in their prospective study, Arrabal- Polo et al., ${ }^{[19]}$ did not observe any benefit with antibiotic prophylaxis, in a population wherein risk factors were not appropriately selected. Satake et al., ${ }^{[20]}$ demonstrated through their retrospective study that the presence of preoperative pyuria seemed to be significantly associated with recurrence in patients diagnosed with NMIBC It is known that intravesical treatment reduces recurrence of bladder tumors, delays progression, and improves overall survival ${ }^{[21]}$. Poletajew et al., ${ }^{[22]}$ have reported in their systematic review that ASBU does not negatively affect the safety and efficacy of intravesical BCG immunotherapy.

The present study is first of its kind in our local population and adds to the limited international evidence on the topic. In the present study, we observed that pre-operative pyuria was a frequent finding in patients presenting with nonmuscle invasive bladder tumor undergoing transurethral resection with BCG instillation and was associated with significantly higher frequency of tumor recurrence which warrants routine screening of such patients for pyuria and anticipated management in positive patients considering increased frequency of tumor recurrence.

A very important limitation to the present study was that we didn't consider the effect of prior antibiotic therapy on treating pyuria and its effect on tumor recurrence nor we compared the results of TURBT with instillation of BCG to TURBT with instillation of mitomycin-c among such patients. Having this information would help in the selection of more appropriate course of management among such patients. Such a study is highly recommended in future research.

\section{CONCLUSION}

Pre-operative pyuria was a frequent finding in patients presenting with non-muscle invasive bladder tumor undergoing transurethral resection with BCG instillation and was associated with significantly higher frequency of tumor recurrence which warrants routine screening of such patients for pyuria. Benefit of this study is to anticipate management in positive patients having non muscle invasive bladder cancer considering increased frequency of tumor recurrence.

ACKNWOLEDGEMENT: None.

CONFLICT OF INTEREST: None.

GRANT SUPPORT \& FINANCIALDISCLOUSRE:

None.

\section{REFERENCES}

1. Ahmad MR, Pervaiz MK, Chawala JA. Risk factors for urinary bladder cancer in Baluchistan. Journal of Ayub Medical College Abbottabad. 2012;24(3-4):135-137.

2. Ahmad MR, Pervaiz MK. Risk Factors of Urinary Bladder Cancer in Sindh, Pakistan by Using the Logit Model. Journal of Statistics. 2014;21(1):195-205.

3. 3. Steinberg RL, Thomas LJ, O'Donnell MA. Bacillus Calmette-Guerin (BCG) treatment failures in nonmuscle invasive bladder cancer: what truly constitutes unresponsive disease. Bladder Cancer. 2015;1(2):105116. 
4. Veeratterapillay R, Heer R, Johnson MI, Persad R, Bach High-risk non-muscle-invasive bladder cancertherapy options during intravesical BCG shortage. Current Urology Reports. 2016;17(9):1-7.

5. Brooks NA, O'Donnell MA. Treatment options innon-muscle-invasive bladder cancer after BCG failure. Indian journal of urology: IJU: Journal of the Urological Society of India. 2015;31(4):312-319. Doi: 10.4103/0970-1591.166475

6. Satake N, Ohno Y, Nakashima J, Ohori M, Tachibana M. Prognostic value of preoperative pyuria in patients with non-muscle-invasive bladder cancer. International Journal of Urology. 2015;22(7):645-649. Doi:10.1111/ iju. 12788

7. Azuma T, Nagase Y, Oshi M. Pyuria predicts poor prognosis in patients with non-muscle-invasive bladder cancer treated with bacillus Calmette-Guérin. Molecular and Clinical Oncology. 2015;3(5):1113-1116.

8. Fukushima H, Kobayashi M, Kawano K, Morimoto S. Effect of preoperative bacteriuria and pyuria on intravesical recurrence in patients with upper tract urothelial carcinoma undergoing radical nephroureterectomy. In Vivo. 2017;31(6):1215-1220.

9. Naeem A, Naseem N, Anwar S, Butt S, Nagi AH. Clinico-pathological pattern, classification and staging of urinary bladder carcinomas-a five yearsexperience at a tertiary care hospital in central punjab. Journal of Ayub Medical College Abbottabad. 2015;27(1):131134.

10. Su C. Risk Factors of Urinary Bladder Cancer: An Epidemiological Study. Journal of Applied and Emerging Sciences. 2004;1(1):107-123.

11. Mubarak M, Kazi JI, Hashmi A, Hussain M, Naqvi SA, Rizvi SA. Urinary Bladder Tumors InSouthern Pakistan: A Histopathological Perspective (Middle East Special Report). 2014;5(3):167-173.

12. Singh JP, PriyadarshiV,PalDK.Aclinicoepidemiological study of young age bladder tumors: An eastern Indian scenario. Journal of Cancer Research and Therapeutics. 2016;12(2):751-754. Doi: 10.4103/0973-1482.154028

13. Altaf J, Mahesar MA, Jatori T. Clinicopathological features of bladder tumors in a single institution in Hyderabad, Sindh, Pakistan. International Journal of Clinical \&Case Studies. 2017;1(1):22-29.

14. Al-Bazzaz PH. Stage of urinary bladder cancer at first presentation. Saudi Journal of Kidney Diseases and Transplantation. 2009;20(4):628-631. Available from: https://www.sjkdt.org/text.asp?2009/20/4/628/53253

15. Biswas RR, Mangal S, Guha D, Basu K, Karmakar D. An epidemiological study of cases of urothelial carcinoma of urinary bladder in a tertiary care centre. Journal of Krishna Institute of Medical Science. 2013;2(1):82-88.

16. Chinnasamy R, Krishnamoorthy S, Joseph L, Kumaresan N, Ramanan V. Clinico-pathological study of bladder cancer in a tertiary care center of South India and Impact of age, gender, and tobacco in causing bladder cancer: a single center experience. International Journal of Science \& Studies. 2016;3(10):72-.77.
17. Mugiya S, Ozono S, Nagata M, Takayama T, Ito T, Maruyama S, et al. Long-term outcome of a lowdose intravesical Bacillus Calmette-Guerin therapy for carcinoma in situ of the bladder: results after six successive instillations of $40 \mathrm{mg}$ BCG. Japanese Journal of Clinical Oncology. 2005;35(7):395-399. Doi:10.1093/jjco/hyi111

18. Joung JY, Lim J, Oh CM, Jung KW, Cho H, Kim SH, et al. Current trends in the incidence and survival rate of urological cancers in Korea. Cancer research and treatment: official Journal of Korean Cancer Association. 2017;49(3):607-615. Doi: 10.4143/crt.2016.139

19. Arrabal-Polo MA, Del Carmen Cano-García M, Arrabal-Martín M, Merino-Salas S. The effect of antibiotic prophylaxis on post-operative infection in patient's undergone flexible cystos-copy. Urology Journal. 2017;14(3):3050-3053.

20. Satake N, Ohno Y, Nakashima J, Ohori M, Tachibana M. Prognostic value of preoperative pyuria in patients with non-muscle-invasive bladder cancer. International Journal of Urology. 2015;22(7):645-649. Doi: 10.1111/ iju. 12788

21. Babjuk M, Böhle A, Burger M, Capoun O, Cohen D, Compérat EM, et al. EAU guidelines on non-muscleinvasive urothelial carcinoma of the bladder: update 2016. European Urology. 2017;71(3):447-461.Doi: 10.1016/j.eururo.2016.05.041

22. Poletajew S, Zapała P, Radziszewski P. Safety and efficacy of intravesical Bacillus Calmette-Guérin immunotherapy in patients with non-muscle-invasive bladder cancer presenting with asymptomatic bacteriuria: a systematic review. Urologia Internationalis. 2017;99(1):1-5.

Author's Contribution:

Khizar Hayat Gondal: Idea conception, and manuscript writing.

Majed Saeed:Data collection, and manuscript review.

Syed Atif Hussain: Correction and revision

Rana Ata ur Rehman: Data analysis.

Ali Shandar Durrani: Data compilation, proof reading and critical analysis.

Muhammad Raheem Sajjad: Conception, design and final review of the manuscript.

Submitted for Publication:14-12-2020 Accepted after revision: 23-10-2021 